\title{
RECONSTRUCTION OF THE SWITCHED RELUCTANCE MOTOR STATOR
}

\author{
Eyhab El-Kharashi - Hany M. Hassanien *
}

\begin{abstract}
The paper re-designs the conventional $6 / 8$ switched reluctance motor (SRM) by a particular way to minimize the losses. The flux loops are shortened by making each two stator teeth incorporated in one magnetic circuit only. Subsequently the flux does not cross in some iron parts of the stator core backs. These unused iron sections are taken off consequently the iron losses decreased. Now the stator consists of three separated sections and they are fixed inside non-magnetic cylinder. The copper losses also are decreased because less copper windings are used to produce the same amount of the output torque as the flux paths become short then the flux density increases. The analysis and comparison of the 6/8 SRM before and after the re-design process are presented. A m files Matlab software is used to simulate the dynamic performance. Then the paper proceeds to examine different control techniques to the new design. The hysteresis and PI controllers are used as classical method to control the SRM. Then the artificial neural network (ANN) is used to test the new control techniques.
\end{abstract}

K e y w o r d s: finite element, matlab, minimizing losses, separated sections, near stator teeth, switched reluctance motor

\section{INTRODUCTION}

The switched reluctance motor is a double salient single excited motor. The stator consists of simple concentric windings (one coil for one pole), and there are no windings or permanent magnets on the rotor. During 1970s and 80s, there was an enormous development of switched reluctance motors, notably at Leeds and Nottingham universities in UK. Work has concentrated on improvements in efficiency, machine thermal design, reduction of torque ripple and acoustic noise, elimination of position sensors, and simplification of power and control circuits. This paper is continuing these researches in a trial to redesigns the SRMs to make them have extreme advantages to compete competitively with the rest of the electrical machines in the industrial applications. The paper re-designs the conventional SRM for particular goal which is minimizing the losses very much. The re-design steps are applied directly on 6/8 SRM to increase its efficiency very much. Simply the idea of re-designing the 6/8 SRM is based on shortening the flux loops by making each two stator teeth incorporated in one magnetic circuit only to increase the flux density so less copper windings are required to produce the same amount of torque. At the same time three parts of the stator core backs are not used because the machine operates as separate magnetic circuit. So these un-used parts can be taken off consequently low losses iron losses [1-4]. Re-designing the 6/8 SRM by this approach minimizes the losses very much. Then the paper used different control techniques to improve the response of the isolated section SRM.

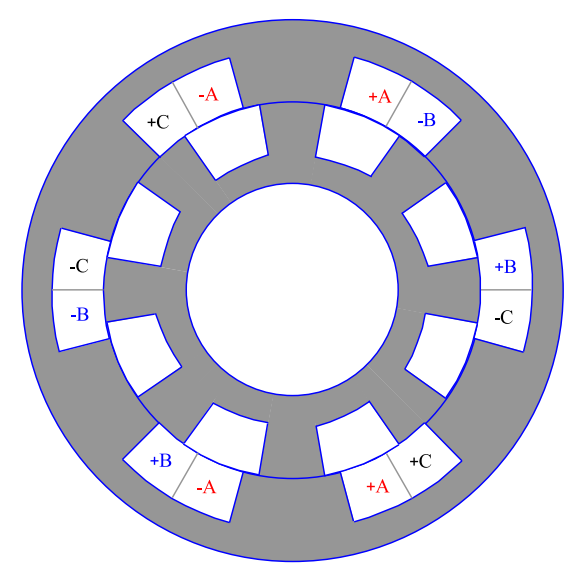

Fig. 1. Conventional 6/8 SRM (unmodified design)

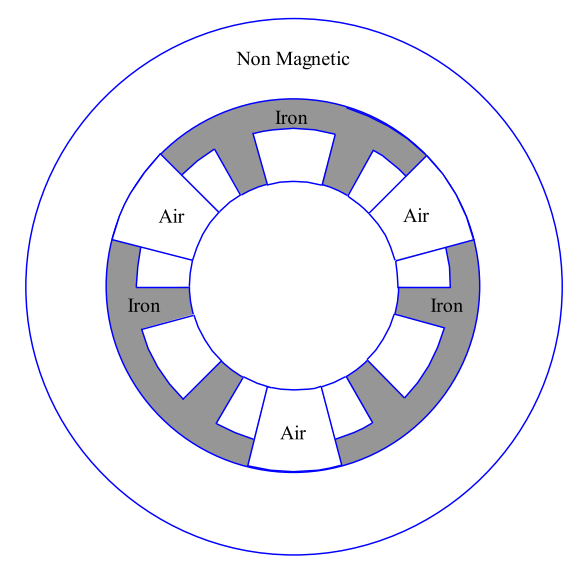

Fig. 2. Proposed re-designed stator

* 1 El-Sarayat Street, Abdou Basha Square, Abbassia, 11517 Faculty of Engineering, Electrical Power \& Machines Department, Ain Shams University, 11517 Cairo, Egypt, eyhabelkharahi@hotmail.com 

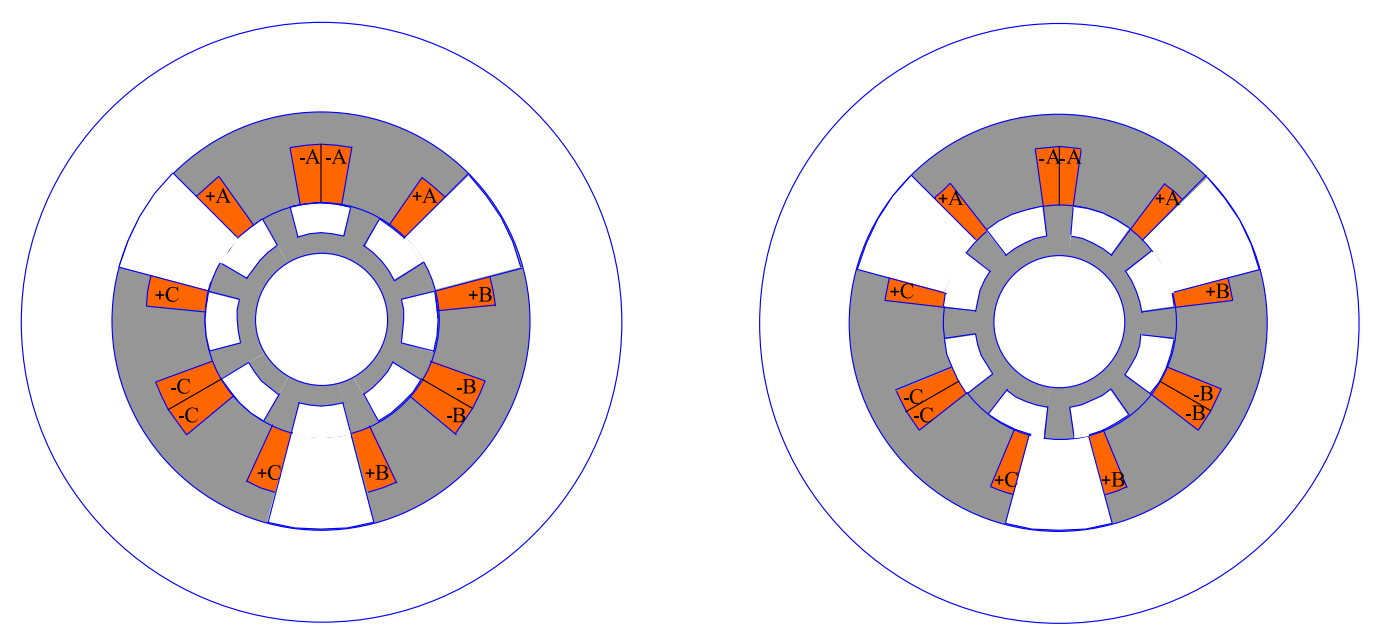

Fig. 3. The aligned and unaligned positions for the re-designed $6 / 8 \mathrm{SRM}$

\section{BACKGROUND}

Figure 1 shows $6 / 8$ three phases conventional toothedrotor SRM before re-designing it to increase the efficiency very much. The stator has three phases each phase has two coils located on two opposite sides of the stator.

The proposed re-designed stator of the $6 / 8 \mathrm{SRM}$ is shown in Fig. 2. It consists of three sections each section belongs to only one phase and has two poles. There are separations between each section.

Figure 3 shows the redesigned 6/8 SRM when phase A in the aligned and in the un-aligned positions respectively.

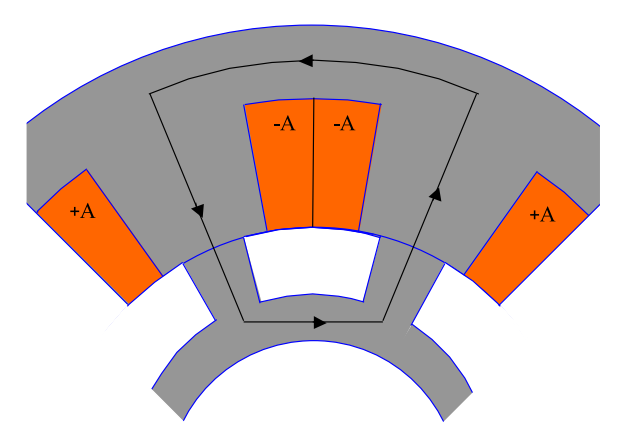

Fig. 4. The two coils of each phase are neighbor

\section{THE PRINCIPLE OF SHORTENING THE FLUX PATHS}

The fundamental equation of the developed torque by any SRM can be written by this expression

$$
\begin{aligned}
T_{e m} & =\frac{P}{\omega}=e i \frac{\partial t}{\partial \Theta}=i \frac{\partial \Psi}{\partial t} \frac{\partial t}{\partial \Theta}=N i \frac{\partial \varphi}{\partial \Theta} \\
T_{e m} & =N i \frac{\partial \varphi}{\partial \Theta}
\end{aligned}
$$

So the specific output torque (Torque/Unit Volume) can be written as the following

$$
\begin{aligned}
\tau_{v} & =\frac{T_{e m}}{V}=\frac{N i}{V} \frac{\partial \varphi}{\partial \Theta} \\
\tau_{v} & =\frac{N i}{V} A \frac{\partial B}{\partial \Theta} \\
\tau_{v} & =K \frac{\partial B}{\partial \Theta}
\end{aligned}
$$

where $K$ is constant.

It is clear from equation (2) that increase the torque per unit volume the only way is to increase the flux density. Since the flux density is directly proportional to (1/ Length of the flux path)

$$
B \alpha(1 / L)
$$

where $B$ is the Flux density and $L$ is the length of the flux loop.

So to increase the flux density the length of the flux path must be decreased. This can be done either by changing the windings configuration or by changing the shape of the magnetic circuit or both.

Shortening the flux path in the proposed modified design is done here by two methods [5-7]:

- Changing the shape of the magnetic circuit by bringing nearer the stator teeth as explained before.

- Changing the windings configuration by making each two coils of each phase neighbor as shown in Fig. 4.

It can be noticed directly from Fig. 4 that the copper windings for each phase are fixed in neighbor slots consequently the end-winding copper losses are decreased very much.

\section{THE PRINCIPLE OF MAXIMIZING THE OUTPUT TORQUE IN THE RE-DESIGNED SRM}

Figure 5 shows the flux-linkage characteristic for switched reluctance motor. The enclosed area between 
Flux - Linkage

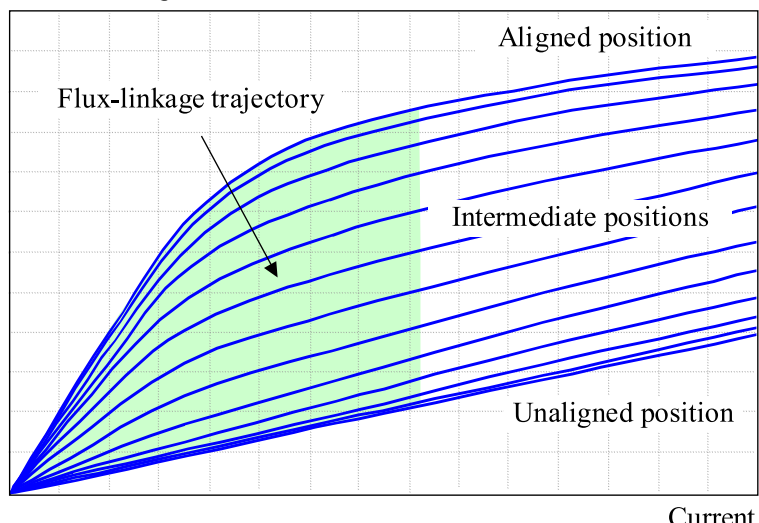

Fig. 5. Flux-Linkage characteristic under current control

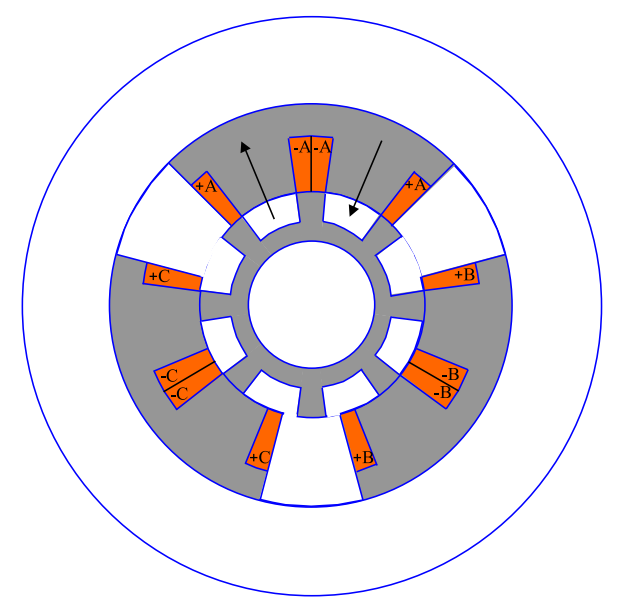

Fig. 7. Open magnetic circuit in the unaligned position of the near stator teeth SRM

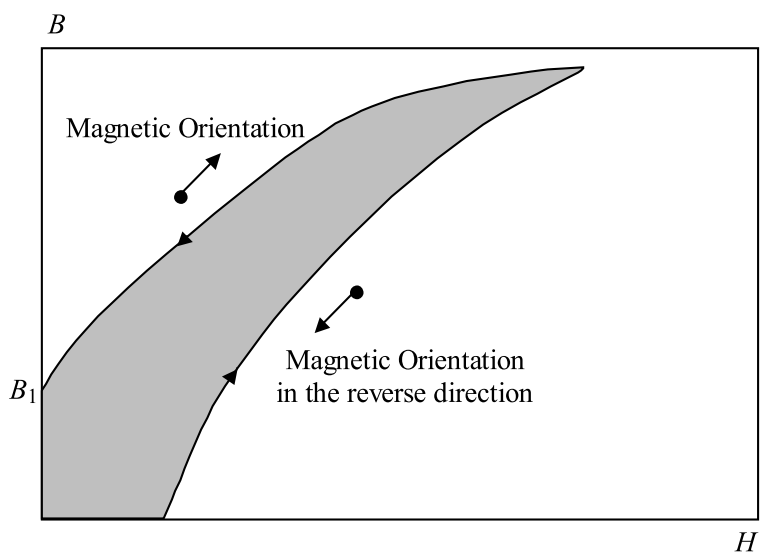

Fig. 8. Eliminating of the reversal current in the modified design minimising the hysteresis loops

the aligned and the unaligned positions is proportional to the output torque.

For the proposed modified design to maximize the area between the aligned and the unaligned positions the inductance must be maximized in the aligned position and to be minimized in the unaligned position. To maximize the inductance in the aligned position of the modified SRM the centers of each two near teeth must be coincided

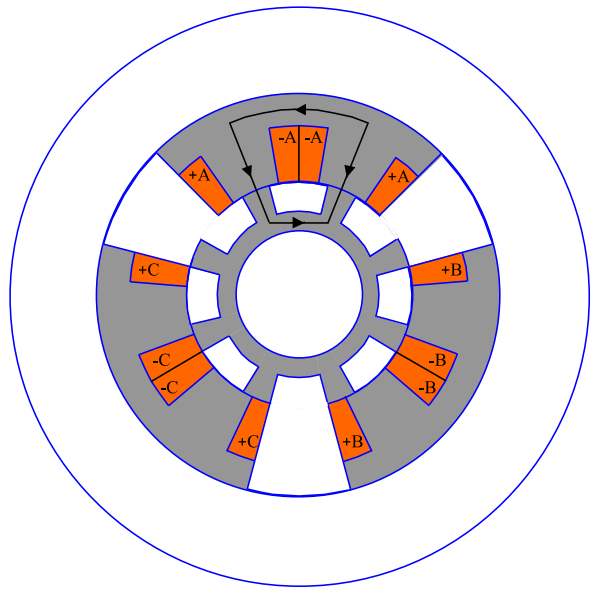

Fig. 6. Short flux path in the aligned position of the near stator teeth SRM

on the centers of two successive rotor poles to shorten the flux path. Figure 6 shows the short flux path in the aligned position of the proposed narrow stator teeth SRM so the maximum possible inductance in the aligned position is achieved. Figure 7 shows the magnetic circuit is open in the unaligned position (no iron parts in front of the energized stator teeth) that means very low inductance. So the design by this approach maximizes the area between the aligned and the unaligned positions consequently maximizes the output torque.

\section{THE PHILOSOPHY OF RE-DESIGNING THE SRM}

The stator teeth in each phase are brought nearer and the magnetic circuit is constructed by a manner that allows for each area of the stator magnetic circuit to be incorporated into one magnetic circuits formed by the motor and its drive only (as shown in Fig. 3). Such a construction greatly reduces the copper losses, end-winding copper losses, eddy current losses and hysteresis losses. Since the flux density increased so less copper windings are required to enable the SRM to give the same amount of the output torque. In addition the windings of each phase are located in neighbor slots so the end-winding copper losses are low. Regarding the iron losses since the frequency of collapsing and building the magnetic fields in the magnetic circuit of the stator is greatly reduced both the hysteresis and the eddy current losses are decreased. Also in the same point of minimizing the iron losses the windings are wrapped about the poles of the stator in a manner that allows the poles of the stator to be energized as pairs of adjacent poles having opposite polarities to create a magnetic circuit between the poles of each pair that makes short flux loops and uni-direction of the current. That means absence of reverse current consequently low hysteresis losses and low eddy current losses. Figure 8 shows the hysteresis loop will decrease because there is no reverse current of excitation, the DC current moves in one direction in each section of the magnetic circuit as the coil fills two neighbor slots. 


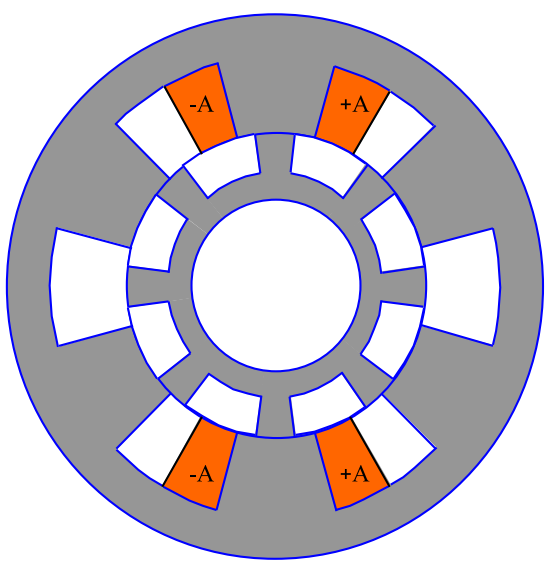

(a) - Phase windings location

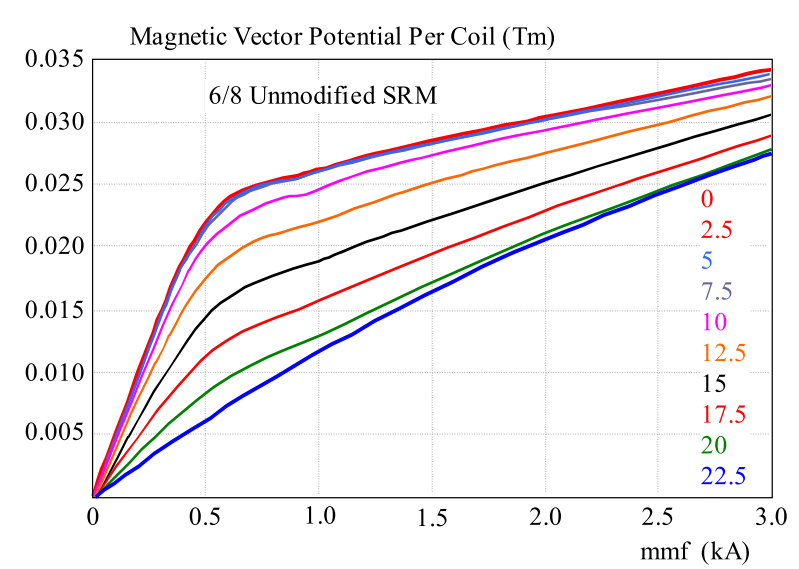

(b) - Magnetic vector potential for different rotor positions
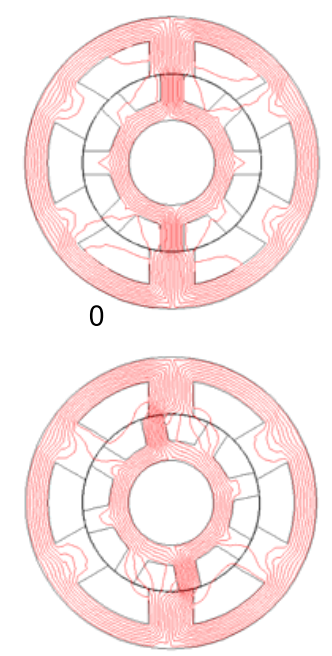

12.5
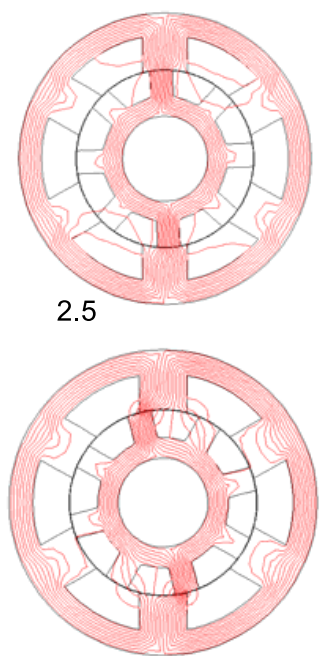

15

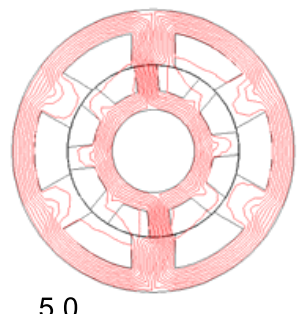

5.0

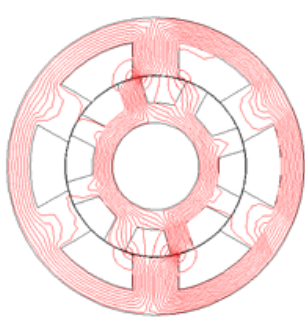

17.5

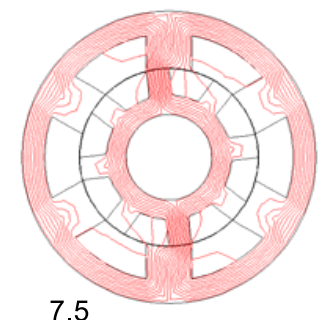

7.5

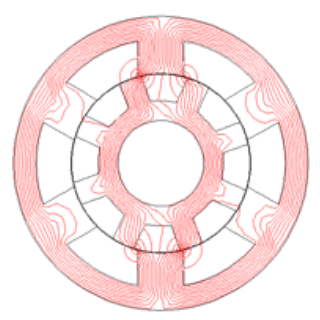

20

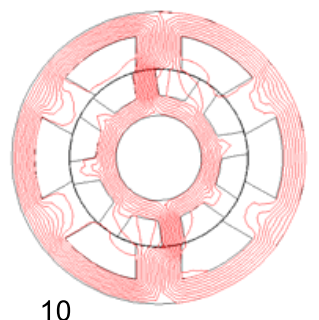

10

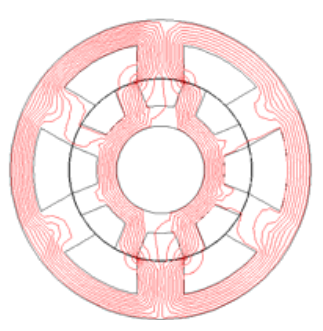

22.5

(c) - Magnetic flux plot for different rotor positions (in degrees)

Fig. 9. Finite Element results of the SRM before any modification

\section{MODELING THE 6/8 SRM BEFORE AND AFTER DESIGN MODIFICATION}

The unmodified SRM has symmetrical three phase windings so only one phase is modeled. The SRM is inherently non-linear because of the double saliency, the air gap is non-uniform. The distribution of the electromagnetic field in any SRM is determined by solving Maxwells field equations with given boundary conditions. Since the closed form solutions to Maxwells equations are very difficult or impossible to obtain for such a machine having complicated geometries and nonlinear materials, the numerical solution of the Maxwells equations becomes a necessity. The method of finite elements (FE) is an excellent numerical method for structures with complicated geometries and material nonlinearities. So, the characteristic of the proposed SRM before and after modification is obtained here by the adaptive finite elements.

\subsection{Modeling the 6/8 Unmodified SRM}

Figure 9 shows the results of modeling the $6 / 8$ SRM by the adaptive finite element before any design modification [8-9].

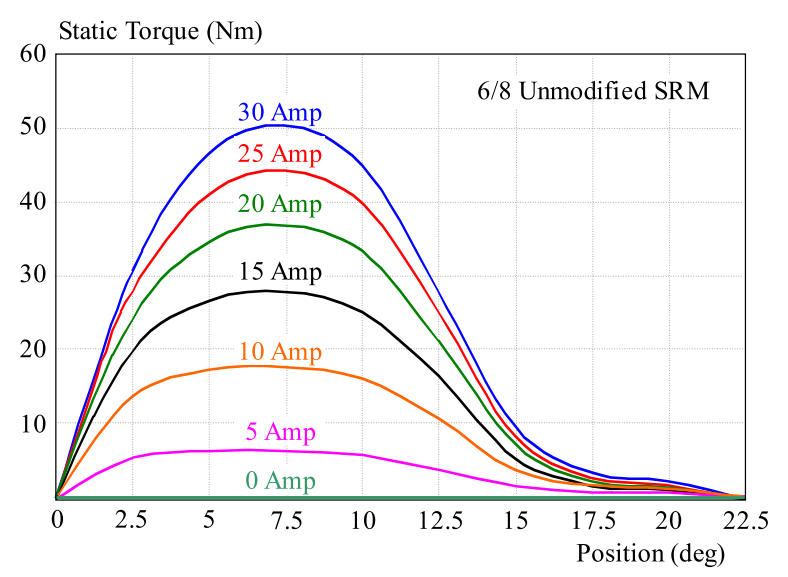

Fig. 10. Static torque characteristic of the unmodified SRM 


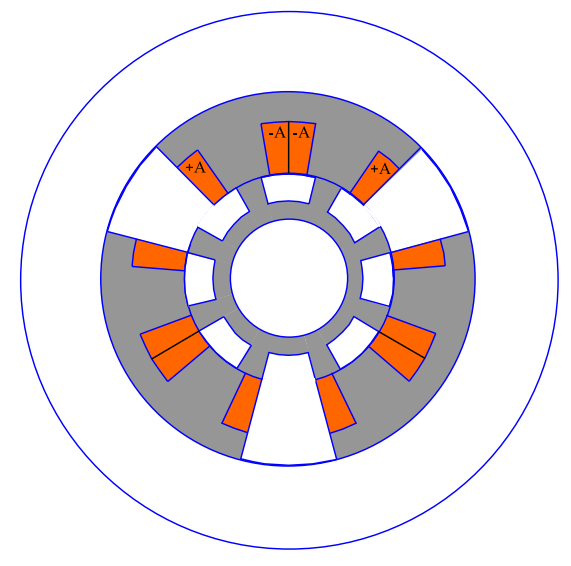

(a) - Phase windings location

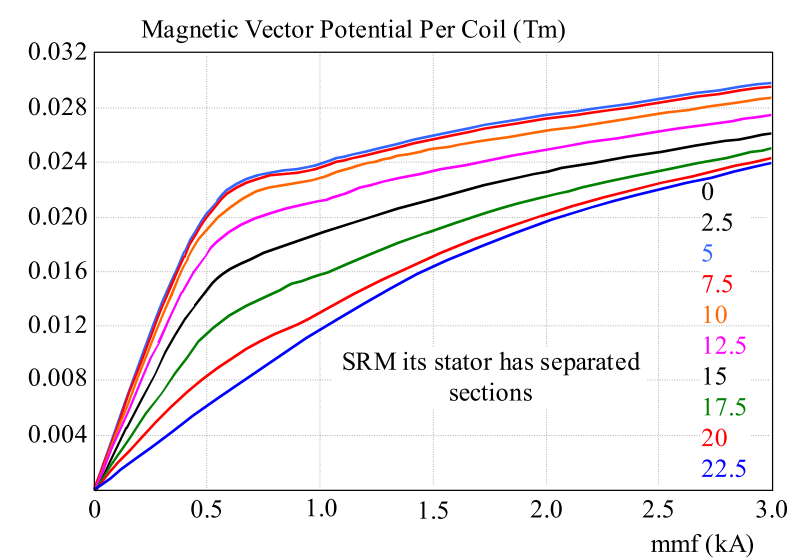

(b) - Magnetic vector potential for different rotor positions

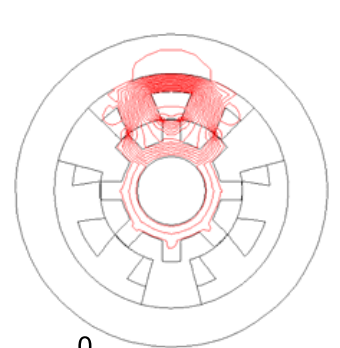

0

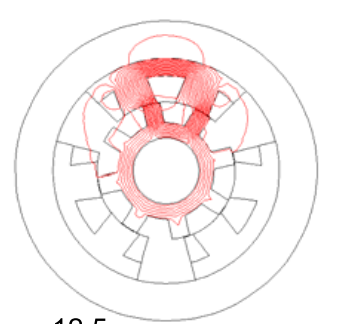

12.5

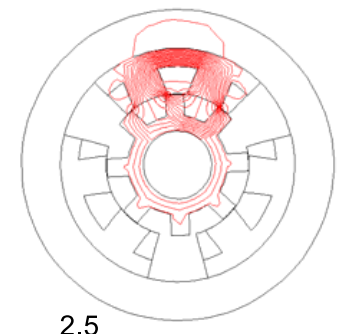

2.5

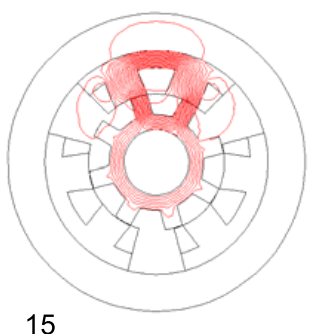

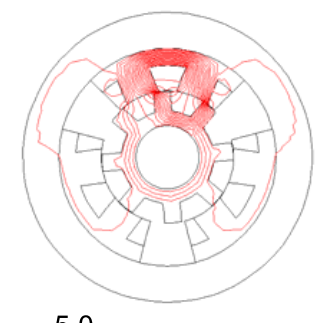

5.0

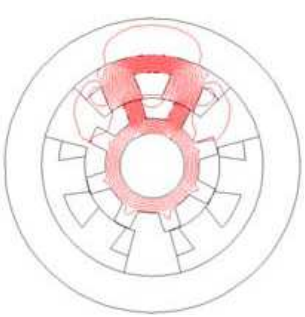

17.5

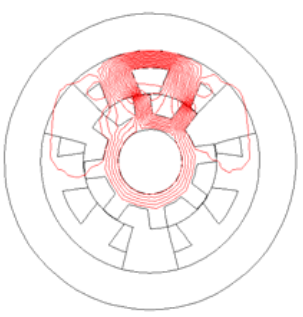

7.5

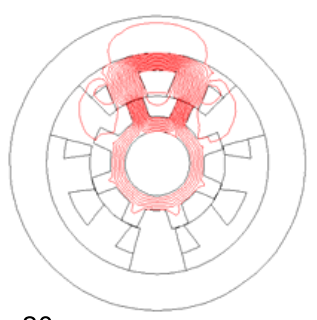

20

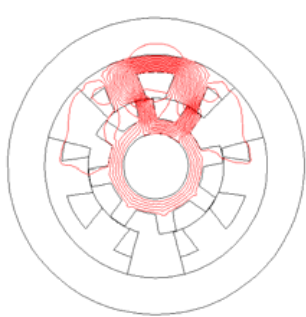

10

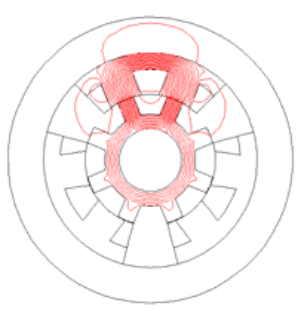

22.5

(c) - Magnetic flux plot for different rotor positions (in degrees)

Fig. 11. The magnetic flux plot and the magnetic vector potential versus the MMF for the $6 / 8$ SRM after re-designing it

Assume there are two coils per phase each coil has 200 turns. Figure 10 shows the static torque characteristic of the unmodified SRM.

\subsection{Modeling the 6/8 after Redesigning the SRM}

Figure 11 illustrates the magnetic flux plot and the magnetic vector potential for different rotor positions of the separated stator SRM [8-9]

Figure 12 illustrates the static torque characteristic for the 6/8 SRM after redesigning it.

Figure 13 shows comparison between the aligned and the unaligned positions for the $6 / 8$ SRM before and after the design modification. The two areas are approximately the same that means the re-designed SRM has the same torque capability but with low losses.

\section{DYNAMIC MODEL OF THE RE-DESIGNED SRM}

The mathematical model of the SRM consists of three basic groups of equations, which are the motor phase equations, the mechanical equation, and the angular speed equation. The motor phase equations describe the electrical behavior of the SRM. The mathematical representation of the motor phase equations are written relative to time in order to study the dynamic behavior of the motor [10-11].

The motor phase equations can be written as follows

$$
\frac{\mathrm{d} \Psi_{k}\left(\Theta_{k}, i_{k}\right)}{\mathrm{d} t}= \pm V-R i_{k} .
$$

The mechanical equation which describes the mechanical motion of the motor can be written as follows

$$
\frac{\mathrm{d} \omega}{\mathrm{d} t}=\frac{1}{J}\left(\sum_{k=1}^{q} T_{k}\left(\Theta_{k}, i_{k}\right)-T_{\ell}\right)
$$




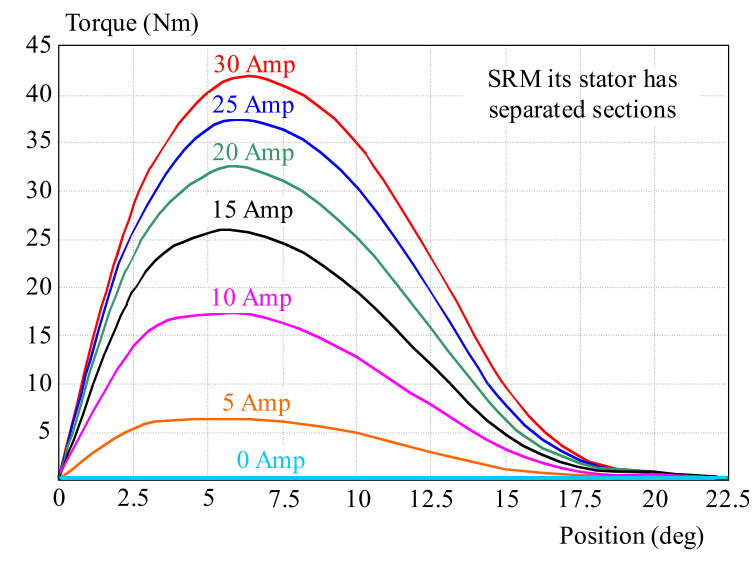

Fig. 12. The Static Torque characteristic for the $6 / 8$ SRM after redesigning it

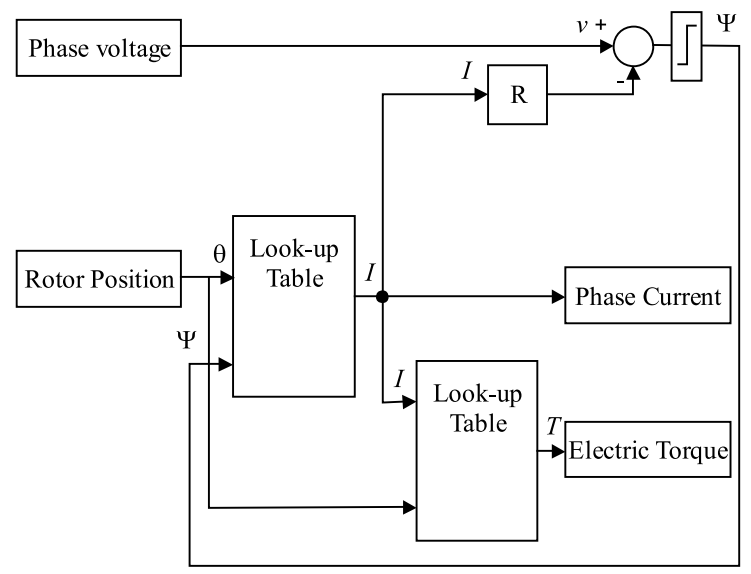

Fig. 14. Block Diagram of SRM Simulation

where $\omega$ is the rotor speed, $(\mathrm{rad} / \mathrm{sec}), J$ is the moment of inertia of both the rotor and load, $\left(\mathrm{kg} \cdot \mathrm{m}^{2}\right), T_{\ell}$ is the load torque, (N.m), $q$ is the number of phases, $T_{k}\left(\Theta_{k}, i_{k}\right)$ is the torque produced by the $k^{\text {th }}$ phase and $\Theta_{k}$ is the rotor position as seen by the $k^{\text {th }}$ phase.

The angular speed equation can be written as follows

$$
\omega=\frac{\mathrm{d} \Theta}{\mathrm{d} t} .
$$

The equations representing the dynamic model are solved simultaneously using a Numerical integration technique with the aid of the motor look-up tables.

\section{APPLYING THE DIFFERENT CONTROL STRATEGIES TO THE ISOLATED STATOR SECTIONS SRM}

\subsection{Hysteresis Control}

Hysteresis control is commonly used in switched reluctance motor (SRM) drives, operating in the low speed region, for limiting the current to the desired value. Figure 14 shows the block diagram of the SRM simulation package. The flux linkage characteristic data is taken from

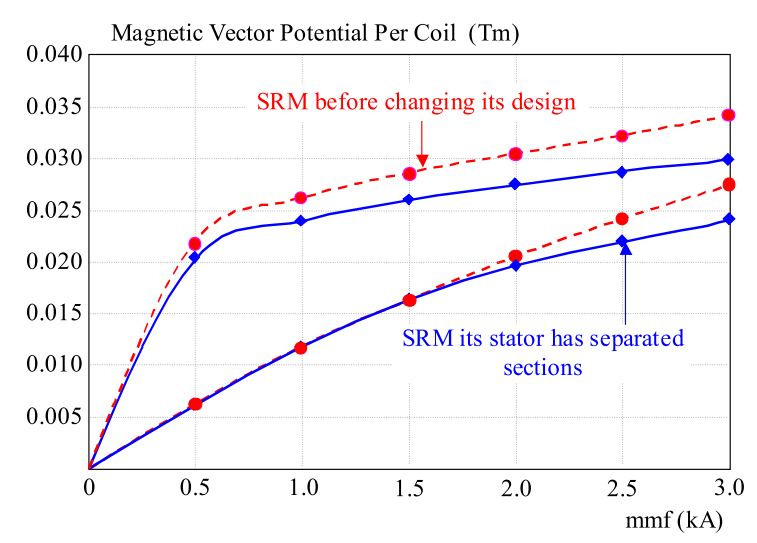

Fig. 13. Comparing the characteristic of the $6 / 8$ SRM before and after design modification

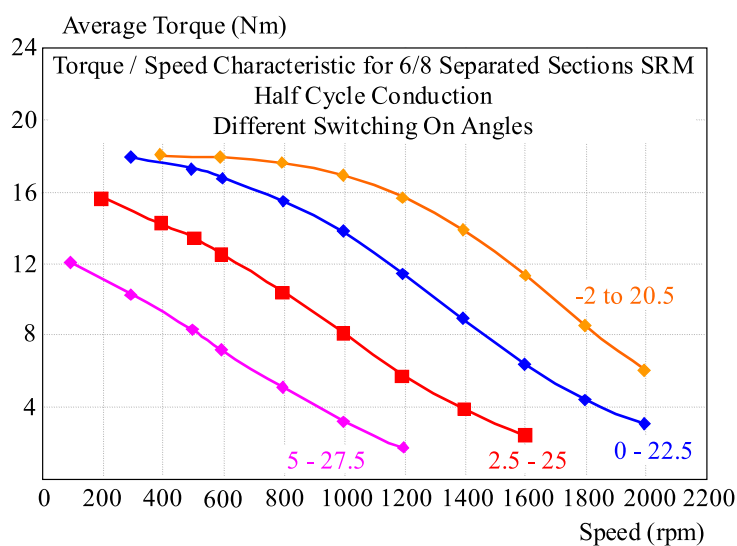

Fig. 15. Torque/Speed characteristic after re-designing the $6 / 8$ SRM

an adaptive finite element solution of the magnetic characteristics. It is stored in tables (one for the flux-linkage characteristic and one for the torque), then loaded in to a simulation of the SRM using Matlab /Simulink [10-11].

Figure 15 illustrates the variation of the torque versus the speed for different switching on angles

Figure 16 shows the dynamic simulation of the $6 / 8$ redesigned SRM at $1000 \mathrm{rpm}$ half cycle conduction and no advance switching on angle.

\subsection{The Conventional PI controller:}

The proportional plus integral (PI) controller is one of the famous controllers used in a wide range in the conventional SRM. So in this section the PI controller will be applied in the isolated stator sections SRM. The output of the PI controller in time domain, is defined by the following equation

$$
V_{c}(t)=K_{p} e(t)+\frac{K_{i}}{T_{i}} \int_{0}^{t} e(t) \mathrm{d} t
$$

where $V_{c}(t)$ is the output of the PI controller, $K_{p}$ is the proportional gain, $K_{i}$ is the integral gain, $T_{i}$ is the integral time constant and $e(t)$ is the instantaneous error signal. 

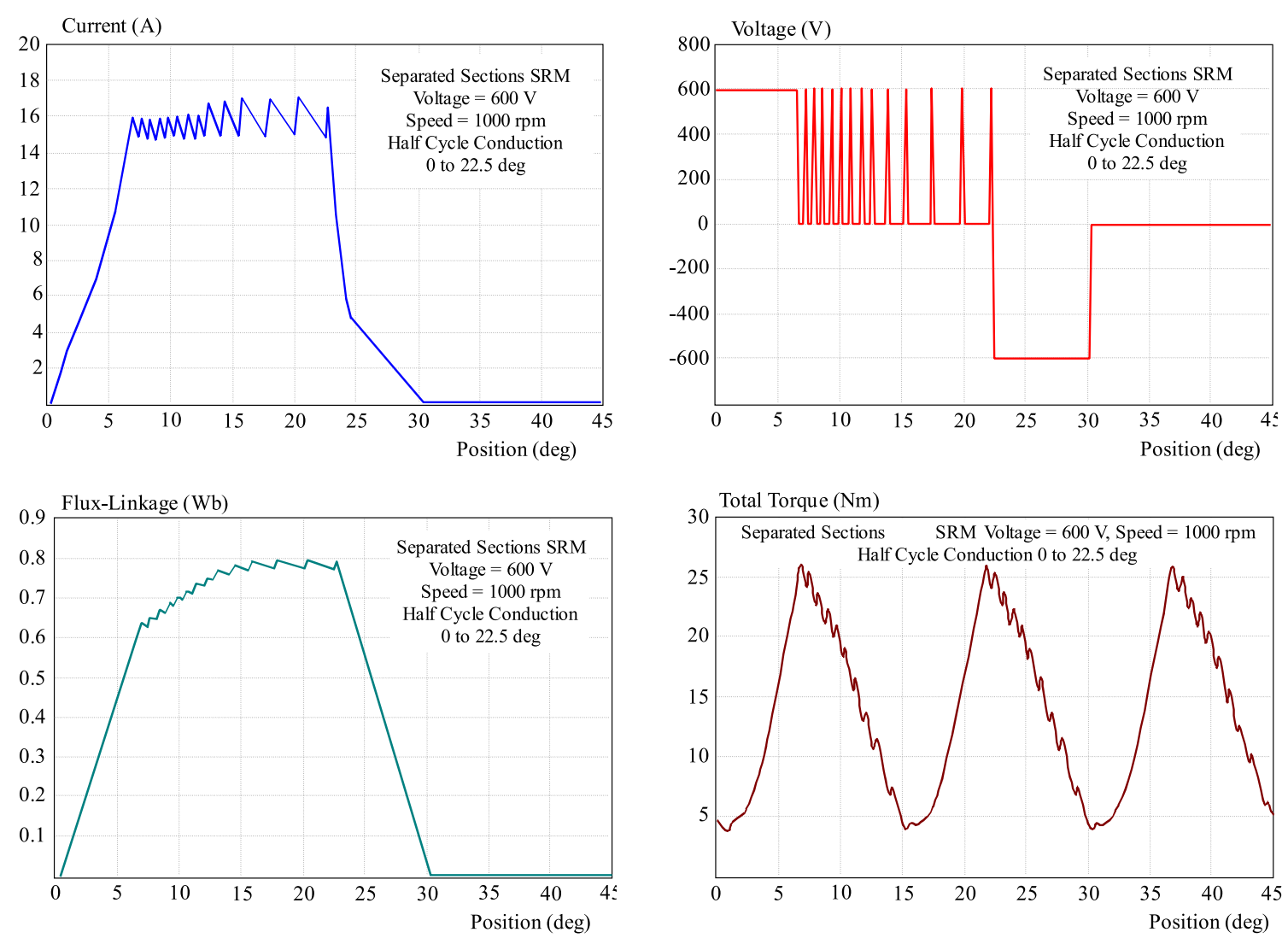

Fig. 16. Dynamic Modeling of the re-designed 6/8 SRM at $1000 \mathrm{rpm}$

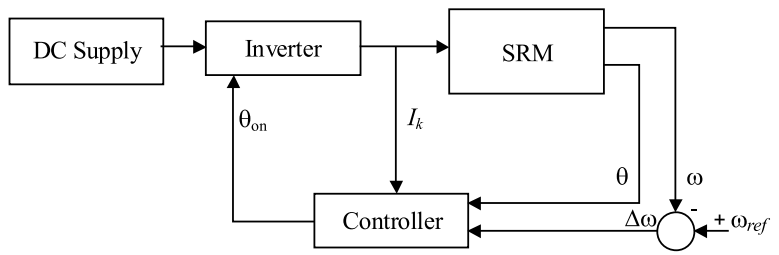

Fig. 17. The SRM control model

The main advantage of adding the integral part to the proportional controller is to eliminate the steady state error in the controller variable. However, the integral controller has the serious drawback of getting saturated after a while if the error does not change its direction. This phenomenon can be avoided by introducing a limiter to the integral part of the controller before adding its output to the output of the proportional controller.

The system under study consists of an Isolated stator sections SRM fed from a DC supply via an inverter, as shown in Fig. 17. The final output of the controller is used to regulate the switching-on angle of the SRM to regulate the motor shaft speed, while the input of the controller is the speed deviation.

The motor speed deviation $\left(e_{w}\right)$, in p.u is given by the following equation

$$
e_{w}=\frac{\omega_{\mathrm{ref}}-\omega}{\omega_{\mathrm{ref}}}
$$

In addition, the controller limits the phase current, within the machine rating, by hystresis chopping during the phase conduction period. The rotor position is also sensed to synchronize the inverter firing with the motor motion.

Then, the new turn-on switching angle $\Theta_{\text {on }}$ (new), which is obtained from the controller output is calculated by the following equation

$$
\Theta_{\text {on }}(\text { new })=\Theta_{\text {on }}(\text { old })-\left[K_{p} e_{w}(t)+\frac{K_{i}}{T_{i}} \int_{0}^{t} e_{w}(t) \mathrm{d} t\right] .
$$

\section{SIMULATION RESULTS}

The analysis of the system under study, shown in Fig 17 , is carried out under the following case study: The motor is started against the full load torque, then, it is subjected to a load disturbance, as shown in Fig 18.

The simulation time interval at different gain values can be divided into three main zones:

(1) The first zone covers the dynamic response during the starting period, as illustrated in Fig. 19.

(2) The second zone covers the dynamic response when the load torque is decreased to $50 \%$ of its initial value, as illustrated in Fig. 20.

(3) The third zone covers the dynamic response when the load torque is returned back to its initial value, as illustrated in Fig. 21. 


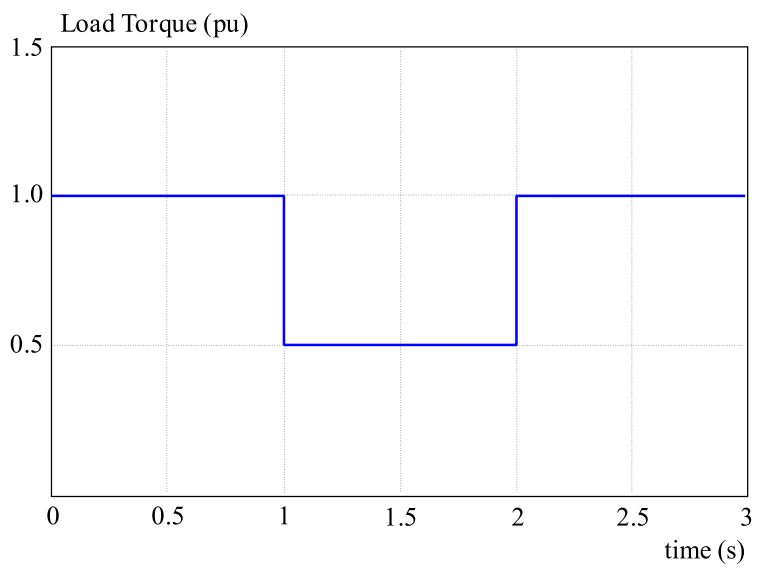

Fig. 18. The variation of load torque (pu), with time (sec)

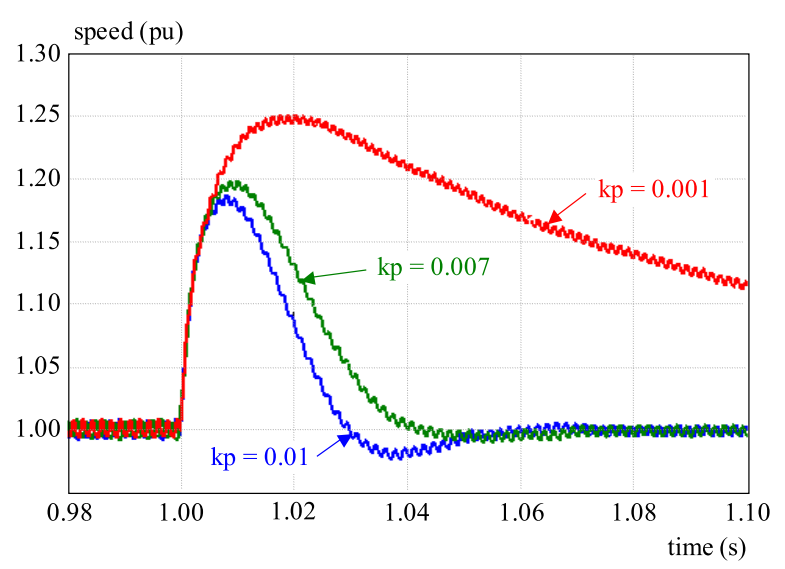

Fig. 20. The dynamic response of the SRM driven by a PI controller during sudden decrease of the load by $50 \%$ (second zone) with $k_{i}=0.5$, and variable gain $k_{p}$

The obtained motor response shows that, As the controller gain kp increases, smaller rise time but higher overshooting during starting is obtained, while during load variations the settling time and overshoot are reduced. This means that, it is better to use a low controller gain during starting period and a higher gain value during load variations.

\subsection{The ANN controller}

Artificial neural networks are computing systems whose structures are simple they can learn from experimental data or from simulations, grasping the essential characteristics of a physical system. ANNs are finding applications in various field of engineering, including adaptive pattern recognition, adaptive signal processing, adaptive dynamic modeling, adaptive control, expert systems etc. In this section the ANN is used to control the isolated stator sections SRM. Artificial neural network (ANNs) have been developed in a wide variety of configurations with some common underlying characteristics. All ANNs attempt achieve good performance via massive interconnection of simple computational elements. Neural networks

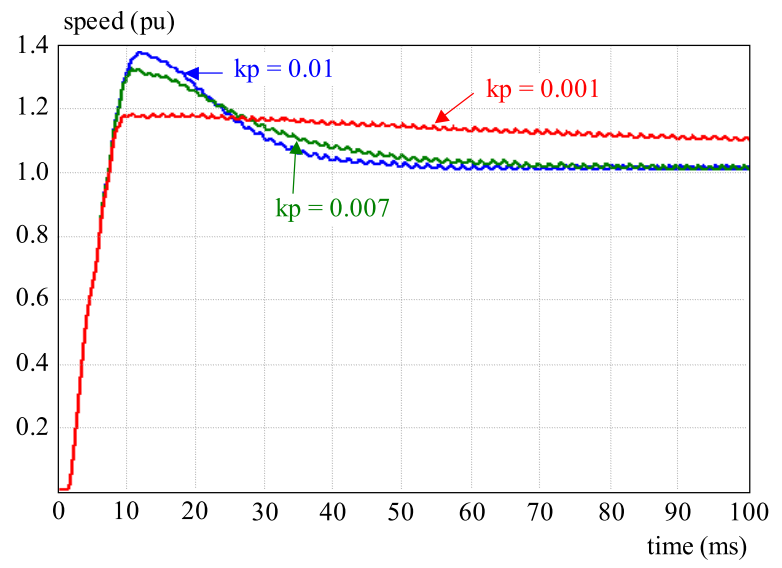

Fig. 19. The dynamic response of the SRM driven by a PI controller during the starting period (first zone) with $k_{i}=0.5$, and variable gain $k_{p}$

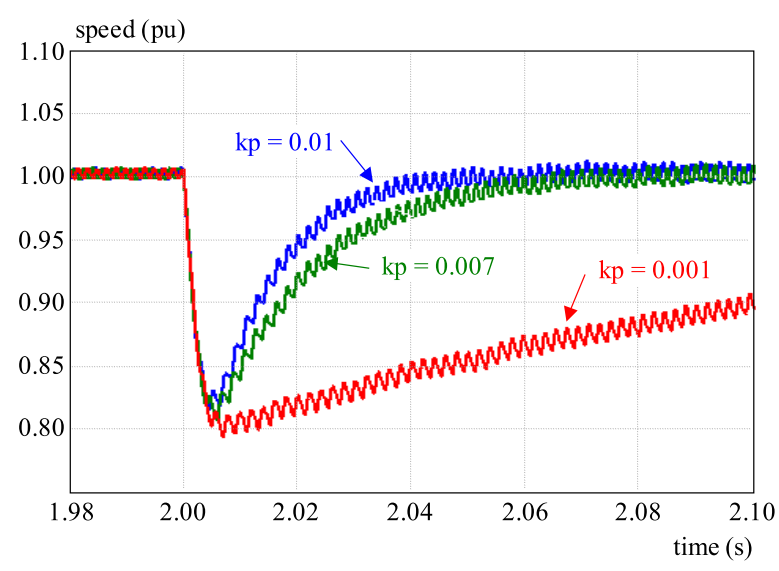

Fig. 21. The dynamic response of the SRM driven by a PI controller during sudden increase of the load by $50 \%$ (third zone) with $k_{i}=0.5$, and variable gain $k_{p}$

are characterized by the model of their neurons, the connections among them and the methods used to train them to do specific tasks.

\section{Basic Principles}

A three layer feed forward structure with three nodes in the input layer is used. The output layer of the ANN consists of only one neuron, while the number of neurons in the hidden layer is to be optimized. The input vector consists of the motor speed error, average torque and the previous output of the ANN. The previous output of the ANN is added to the input vector as a stabilizing signal. The activation function used is the sigmoid logistic function in both hidden and output layer [13-14]

The output of the ANN after being rescaled is used to control the motor phase switching-on angle.

Increasing the number of neurons in the hidden layer has the advantages of reducing the rise time at starting, reduces the percentage overshoot (POS) and settling time during load variation. Also, on the other hand, the POS is increased during starting. 


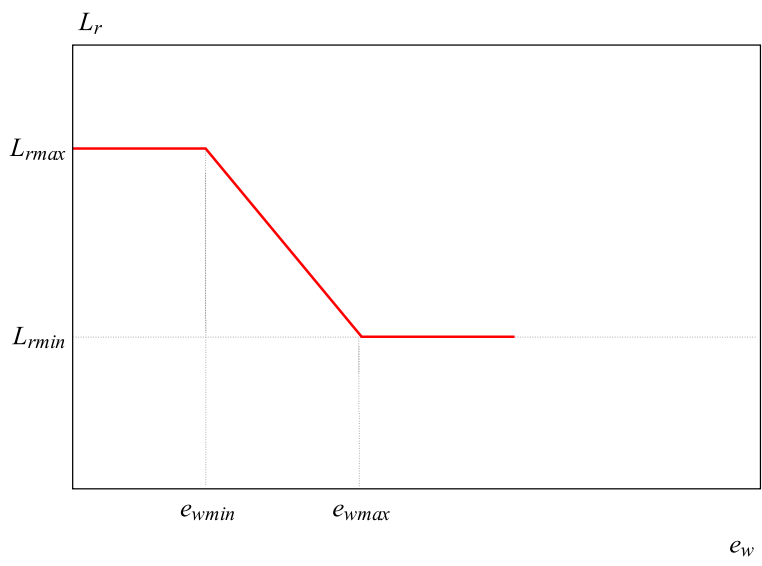

Fig. 22. The rule for varying the learning rate according to the speed error

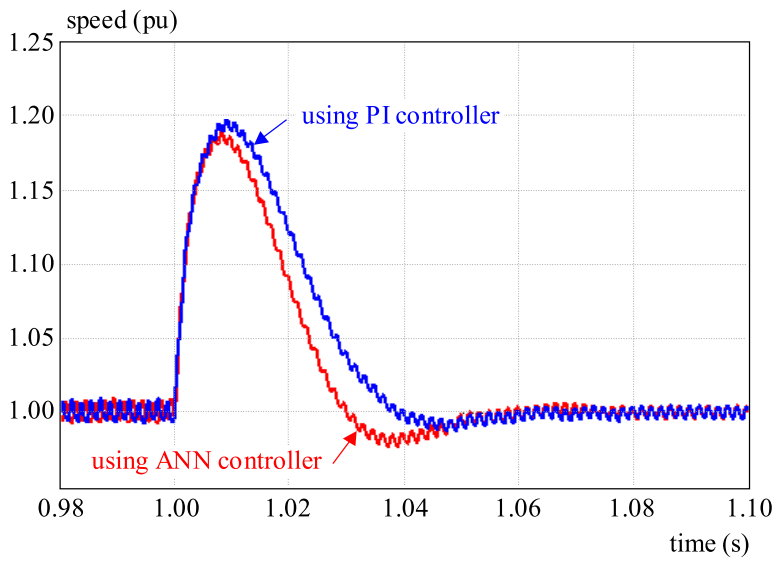

Fig. 24. The dynamic response of the motor during the second zone, using the ANN controller as compared with the PI controller of gains $k_{p}=0.01$ and $k_{i}=0.5$

The small number of neurons in the hidden layer reduce the POS during starting with a slower response. The main disadvantageous appears in increasing the POS during the load disturbance [15-16].

The effect of increasing the value of the learning rate is similar to the effect of increasing the gain of the PI controller and the same effect of increasing number of neurons in the hidden layer. Varying the number of neurons in the hidden layer is not available practically with the on-line adaptive ANN.

The suggested rule for varying the learning rate according to the motor speed error is shown in Fig. 22. Where $e_{w \min }=0.01, e_{w \max }=0.1, L_{e \min }=0.008$, $L_{r \max }=0.04$.

\section{CALCULATING THE \\ PERCENTAGE INCREASE IN THE EFFICIENCY OF THE SRM}

In order to predict an approximated percentage increase in the efficiency the percentage reduction in the copper losses must be calculated [10-11]. The dimensions of the SRM are in Appendix A The half slot area in the

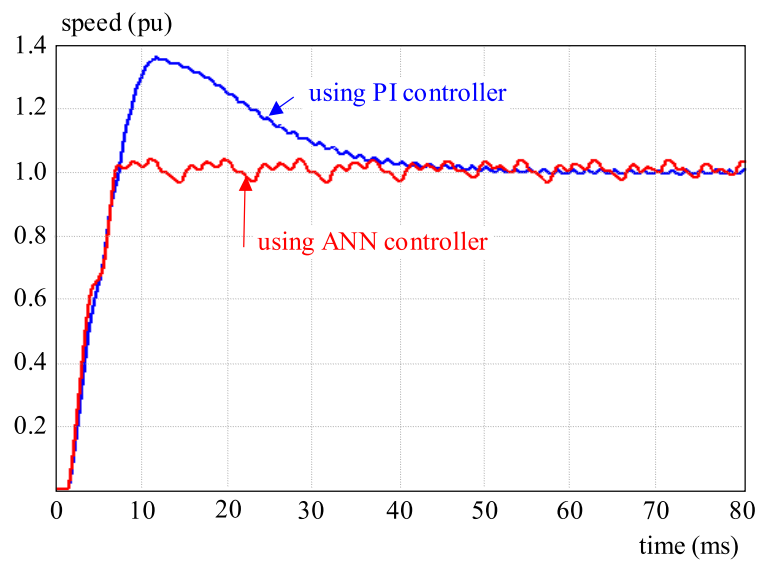

Fig. 23. The dynamic response of the motor during starting provided with the ANN controller as compared with the PI controller of gains $k_{p}=0.01$ and $k_{i}=0.5$

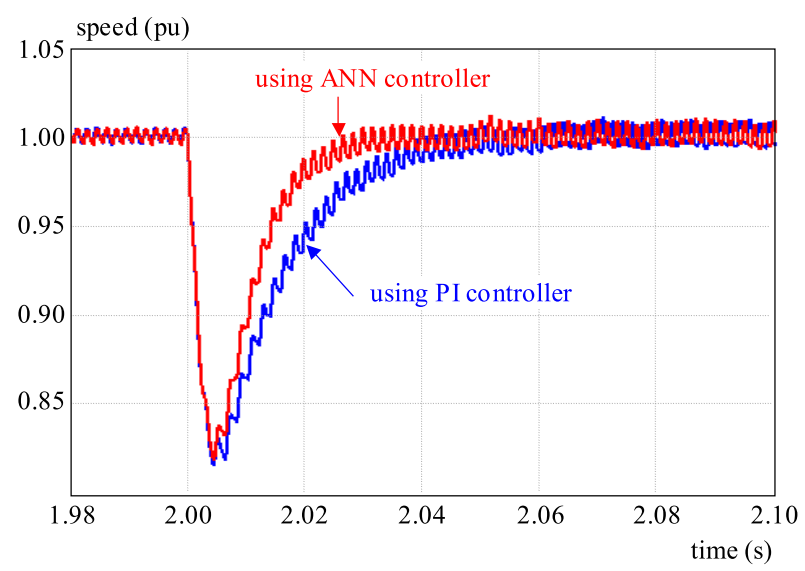

Fig. 25. The dynamic response of the motor during the third zone, using the ANN controller as compared with the PI controller of gains $k_{p}=0.01$ and $k_{i}=0.5$

unmodified is $\mathrm{SRM}=293 \mathrm{~mm}^{2}$ Since 12 half slots are filled with copper windings as shown in Fig. 1 so the total volume of the copper $=$ Length of the $\mathrm{SRM} * 12 * 293$.

The area of half slot in the narrow stator teeth SRM = $167 \mathrm{~mm}^{2}$. Since 12 half slots are filled with copper windings as shown in Fig. 3 so the total volume of the copper $=$ Length of the SRM $* 12 * 167$. So percentage reduction in the copper losses $=100 * \frac{293-167}{293}=43 \%$.

\section{CONCLUSION}

When the efficiency of the SRM is the key-target the machine designer must modify the conventional design of the SRM to minimize its losses very much without sacrificing any of its advantages. The paper addresses a simple design modification and its application on a conventional three phases $6 / 8 \mathrm{SRM}$ to minimize both the copper losses and the iron losses very much without sacrificing any of the well known advantages of the SRM. Each two stator teeth are brought nearer and the stator is divided to three separated sections each section is incorporated in one magnetic circuit only. The design by this approach minimizes both the copper losses and the 
iron losses very much. The paper introduced the basics of this modification, theoretical background, modeling, analysis and comparison with the equivalent unmodified SRM to validate the results. The results show the separated sections SRM produces the same amount of torque of the unmodified SRM with very low losses, the calculation shows the percentage reduction in the copper losses was $43 \%$. The static and dynamic simulations are shown. The different control techniques which are used illustrate improvement in the response.

\section{Appendix A}

Stator outside diameter $150 \mathrm{~mm}$,

Stator axial length $150 \mathrm{~mm}$,

Number of stator teeth 6 ,

Number of rotor teeth 8 ,

Stator bore diameter 91.4 ,

Air gap length $0.3 \mathrm{~mm}$,

Number of phases 3 .

\section{REFERENCES}

[1] PEACHEE, C. T.: Washing Machine Including a Segmented Stator Switched Reluctance motor, WO Patent 02/077352.

[2] EDRINGTON, C. S.-KRISHNAMURTHY, M.-FAHIMI, B. Bipolar Switched Reluctance Machines: A Novel Solution for Automotive Applications, IEEE Transactions on Vehicular Technology 54 No. 3 (May 2005).

[3] TANG, Z.-PILlAY, P.-OMEKANDA, A. M.-LI, C.-CETINKAYA, C. : Youngs Modulus for Laminated Machine Structures With Particular Reference to Switched Reluctance Motor Vibrations, IEEE Transactions on Industry Applications 40 No. 3 (May/June 2004).

[4] El-KHARASHI, E.: Design and Analysis of Rolled Rotor Switched Reluctance Motor, Journal of Electrical Engineering \& Technology 1 No. 4 (2006), 472-481, the Korean Institute of Technology.

[5] LIU, Y.-PILLAY, P.: Improved Torque Performance of Switched Reluctance Machines by Reducing the Mutual Saturation Effect, IEEE Transaction on Energy Conversion 19 No. 2 (June 2004).

[6] El-KHARASHI, E. : Design and Predicting Efficiency of Highly Nonlinear Hollow Cylinders Switched Reluctance Motor, Elsevier: An International Journal of Energy Conversion and Management 48 No. 8 (Aug 2007), 2261-2275, DOI on ScienceDirect doi: 10.1016/j.enconman.2007.04.006.

[7] El-KHARASHI, E.: A Rotor Consisting of Two Iron Cylinders for Switched Reluctance Motor, The Eleventh International Middle East Power System Conference MEPCON2006, December 19-21, vol. 1, El-minia, Egypt, 2006, pp. 377-384.

[8] VENKATESAN, G.-ARUMUGAM, R.-VASUdEVAN, M. -PARAMASIVAM, S.-VIJAYAN, S. : Modeling and Simulation of a Novel Switched Reluctance Motor Drive system with Power Factor Improvement, American Journal of Applied Sciences 3 No. 1 (2006), 1649-1654.

[9] KRIShnamurthy, M.-EDRINGTON, C. S.-FAHIMI, B. : Prediction of Rotor Position at Standstill and Rotating Shaft Conditions in Switched Reluctance Machines, IEEE Transaction on Power Electronics 21 No. 1 (Jan 2006).
[10] KRISHNAMURTHY, M.-EDRINGTON, C. S.-EMADI, A. -ASADI, P.-EHSANI, M.-FAHIMI, B.: Making the Case for Applications of Switched Reluctance Motor Technology in Automotive Products, IEEE Transactions on Power Electronics 21 (May 2006).

11] RAFAJDUS, P.—HRABOVCOVÁ, V.-HUDÁK, P.—FRANKO, M.: Torque Optmization of Switched Reluctance Motor, Workshop on Variable Reluctance Electrical Machines, Technical University of Cluj-Napoca, $17^{\text {th }}$ Sept 2002.

12] HENRIQUES, L. O. P.-BRANCO, P. J. C.-SUEMITSU, W. I.-ROLIM, L. G. : Two Automatic On-Line New Schemes to Compensate the Torque Ripple of Switched Reluctance Machine: with and without Torque Signal Measurement, Springer Journal, Coppe-Univ. (2002), 852-857.

[13] HenRiQues, L. O. P.-ROLiM, L. G.-SUEmitsu, W. I.-BRANCO, P. J. C.: Torque Ripple Minimization in a Switched Reluctance Drive by Neuro-Fuzzy Compensation, IEEE Transactions on Magnetics 36 No. 5 (Sept 2000), 3592-3594.

[14] De ARAujo Porto henRIQUes, L. O.-BRANCO, P. J. C.-ROLIM, L. G. B.-SUEMITSU, W. I. : Proposition of an Offline Learning Current Modulation for Torque-Ripple Reduction in Switched Reluctance Motors: Design and Experimental Evaluation, IEEE Transactions on Industrial Electronics 49 No. 3 (June 2002), 665-676.

[15] HASANIEN, H.. M.-SAAD, N. H.-MOSTFA, M. A.-BADR, M. A. : Speed Control of Axial Laminations Switched Reluctance Motor Provided with Digital Pole Placement Controller, Proc. of the International Conference on Electrical Machines (ICEM), 2006, pp. 376-380.

[16] HASANIEN, H. M.: Speed Control of Axial Laminations Switched Reluctance Motor, PhD thesis, Ain Shams University, Faculty of Engineering, Cairo, Egypt, 2007.

Received 12 August 2011

Eyhab El-Kharashi received his $\mathrm{PhD}$ degree in the electrical machines design from University of Newcastle upon Tyne, UK in 2003 and BSc (first class honours) and MSc degrees in electrical Power and Machines Engineering from Ain Shams University, Cairo, Egypt, in 1994 and 1997 respectively. Now he is an associate professor in the Department of Electrical Power and Machines, Faculty of Engineering, Ain Shams University, Cairo, Egypt. His research interests include modeling, simulation, control of electromechanical drive systems, electrical traction, neural network, power systems; theory, analysis and design of novel electrical machines.

Hany M. Hassanien was born in Cairo, Egypt on May 20, 1976. He received his BSc, MSc and PhD degrees in Electrical Engineering from Ain Shams University, Faculty of Engineering, Cairo, Egypt, in 1999, 2004, and 2007 respectively. He is an Assistant Professor at the Electrical Power and Machines Department, Faculty of Engineering, Ain Shams University. Currently, he is on leave as Assistant Professor at Electrical Engineering Department College of Engineering, King Saud University. His research interests include machines design, modern control techniques, electrical drives, and artificial intelligence applications on electrical machines and renewable energy systems. Dr. Hasanien is a Senior member of the Institution of Electrical and Electronics Engineers (IEEE), Power and Energy Society (PES), and Industrial Electronics Society (IES). His biography has been included in 'Marquis Who's Who' in the world for its 28th edition, 2011. 